Denmark than it is anywhere else. Their numbers, and the number of non-tenured assistant professors, nearly doubled between 2006 and 2013, reaching 3,598, whereas the number of associate professorships grew by less than $25 \%$, to 4,443 . Of these, just $5-10 \%$ become available each year. Many people with postdocs work hard on short-term contracts while waiting for a vacant professorship. Most will wait in vain.

Many junior scientists do multiple postdocs, in part to further their dream of a professorship and partly because they see no clear alternative. But it is clear from our survey of and interviews with former postdoc researchers (which we conducted between 2014 and 2015) that aiming for academia through multiple postdocs is unlikely to bring career satisfaction. The 400 participants had done postdocs between 2007 and 2014 at DNRF centres of excellence (research units embedded in Danish universities or research institutions). Of the $20 \%$ who now work in industry as researchers or managers, $85 \%$ said that they were very or fairly satisfied with their current job. And they reported greater satisfaction with their job security and career opportunities than did those in academia, including researchers currently doing a postdoc.

Yet half of the interviewees and survey respondents consider it unlikely or very unlikely that they will get a non-academic job, mainly because they think that they lack the necessary competencies. Most postdoc researchers whom I have interviewed also believe that they are on the path to a career in academia - though the disheartening truth is that even if you are a great scientist, there is often no place for you there. But it is clear from our survey and interviews that many people do up to three postdocs, increasing the risk that a potential employer, especially in industry, will see them as too specialized.

Ask yourself and your supervisor during your first postdoc whether you should aim beyond an academic career - and demand career advice and mentoring from people who work in relevant research-based industries or in the public sector. You need strong and specific career advice, including exposure to role models with careers outside academia. Only $20 \%$ of the postdocs in our survey had received such guidance.

You must control your own career. Don't languish in a sector in which there might be no position for you, even if it seems risky to leave academia. A willingness to take risks is characteristic of a great professional life. As the Danish philosopher Søren Kierkegaard said: "To dare is to lose one's footing for a while. Not to dare is to lose oneself." -

Søren-Peter Olesen is director of the Danish National Research Foundation in Copenhagen.

\title{
Germany to fund tenure-track posts
}

\section{Federal government will create 1,000 professorships.}

\section{BY AMBER DANCE}

$\longrightarrow 7^{\mathrm{s}}$ erman chancellor Angela Merkel and state prime ministers have signed a $€ 1$-billion (US\$1.1-billion) agreement to fund 1,000 new tenure-track professorships, in the hopes of retaining and recruiting top academic talent in the nation.

According to the Nachwuchspakt ('junior pact'), as the contract is known, the federal government will pay young professors as they work towards tenure, after which state-funded universities will assume financial responsibility.

"It's the first time that the federal government, as far as I know, is investing such a lot of money into the careers of young scientists," says Christian Schäfer of the German Academic Exchange Service in Bonn. The agreement, signed on 16 June, reflects an effort to improve the job situation for young researchers in Germany, where tenure-track positions are rare. Scientists typically work in temporary posts until they are eligible for a faculty spot - usually not until their early 40 s, at which point it is difficult to start a nonacademic career.

Schäfer and many young researchers say that the agreement is a positive

\section{"Because of the perceived insecurity, there are great minds who leave the academic world."}

step - but that more needs to be done. "It's better than nothing," says Andreea Scacioc, a structural biologist in Göttingen, who earned a PhD in 2014. "But it's too little."

Every year, about $28,000 \mathrm{PhD}$ and medical students graduate from German universities. There are about 25,000 actively employed professors, according to the German Association of University Professors and Lecturers (DHV). The Society of Junior Professors, a national advocacy group for junior academics, has argued that tenure track ought to be the default entry-level post for junior academics, and DHV officials estimate that 7,500 more professorships are needed to offer young academics a better future.

The pact will run from 2017 to 2032 and involve two major hiring waves, in 2017 and 2019. Universities must apply for funds to set up these professorships. The federal government will fund the first six years of a professor's position, as well as two extra years for those who earn tenure. But researchers will still need to obtain grant funding because the pact funds will mainly cover their salary. Fifteen percent of the total money will be set aside for universities to develop research career paths - for example, by instituting other kinds of permanent positions.

German universities tend to hire few permanent professors. Those who are hired run a 'mini-department', says Jakob Macke, a computational neuroscientist at the Max Planckaffiliated neuroscience-research centre Caesar in Bonn. The general route to independence has been to perform a Habilitation - a sort of second thesis - under a professor's guidance, which qualifies a postdoc for a professorship.

Starting in the late 1990s, German institutions introduced various sorts of junior professorships and group-leader positions. These allow young researchers to skip the Habilitation and run their own labs, but they are temporary - and many researchers still do a Habilitation. "Because of the perceived insecurity, there are great minds who leave the academic world," says Jens Pöppelbuß, a junior professor of industrial services at Germany's University of Bremen. Other talented scientists decamp for nations that offer more direct career paths.

The Nachwuchspakt arose in part from changes to Germany's 2005 Excellence Initiative, which funded graduate schools; 'clusters of excellence' that offered international-scale training and research facilities; and competitive research programmes. The original initiative will expire in 2017, and the new version - also signed on 16 June - will drop its focus on graduate schools and early-career scientists, leaving a hole that the Nachwuchspakt will fill.

But Scacioc points out that the pact does not set a quota for hiring women. She fears that it could perpetuate the status quo in which men are more likely to secure professorships, thanks in part to their winning more prestigious awards. Requirements for hiring and tenure will need to be clear and transparent to keep the process fair and to ensure that the best candidates get the positions, says Jule Specht, a personality psychologist at the Free University of Berlin.

"Money from the federal government can only provide some incentives," says Pöppelbuß. "All the different federal states and all universities must commit themselves to establishing more reliable and predictable career paths in academia." 


\section{CORRECTION}

The Careers News article 'University jobs:

Germany to fund tenure-track posts' (Nature 535, 190; 2016) incorrectly identified

Angela Merkel as Germany's President. She

is, of course, its chancellor. 